\title{
Isatis Glauca Subsp. Sivasica Extract Contributes To The Diabetic Wound Healing Process By Increasing The Collagen And Nitric Oxide Content
}

\author{
Kaan Kaltalioglu1 ${ }^{1 D}$ Sule Coskun Cevher ${ }^{2}$ (D) \\ ${ }^{1}$ Giresun University, Espiye Vocational School, Giresun, Turkey \\ ${ }^{2}$ Gazi University, Department of Biology, Ankara, Turkey
}

\section{ABSTRACT}

satis $L$. genus is highly endemic in Turkey and it is traditionally suggested for the wound 1 management. In this study, we have reported the effect of the I. glauca subsp. sivasica extract on the diabetic wound healing process. A diabetic model was generated in Wistar rats using streptozotocin injection. The rats were divided into two main groups: the control group and the Isatis group. Full thickness excisional skin wounds were created by using a biopsy punch. The Isatis group was treated with single daily dose I. glauca subsp. sivasica extract $(50 \mathrm{mg} / \mathrm{kg})$. The rats were sacrificed on day 3 or day 7 after wounding. The dominant phenolic compounds identified with RP-HPLC-DAD from the Isatis extract were the benzoic acid and the vanillic acid. The Isatis extract significantly accelerated the wound healing process considering the wound closure rates (WCR). Moreover, the levels of collagen and nitric oxide were elevated on day 3 and day 7 by Isatis administration in the diabetic wound tissue. This data suggests that, for the first time, I. glauca subsp. sivasica extract may have the potential to promote the impaired wound healing in patients with diabetes.

Keywords:

Collagen; Diabetes mellitus; Isatis glauca subsp. sivasica; Nitric oxide; Wound healing.

\author{
Article History: \\ Received: 2021/02/25 \\ Accepted: 2021/05/23 \\ Online: 2021/06/30
}

Correspondence to: Kaan Kaltalioglu, Giresun University, Espiye Vocational School, 28600, Giresun, Turkey E-Mail:kaan.kaltalioglu@gmail.com Phone: +90 (454) 3101430 Fax:+90 (454) 3101431

\section{INTRODUCTION}

$\mathrm{P}$ lants are traditionally used for medicinal purposes in the treatment of many diseases. Isatis L. genus (Brassicaceae), locally known as çivitotu in Turkey, has about 31 species and 15 subspecies in Turkey [1]. Isatis L. members are folkloric plants and are used both as an indigo plant and as a medicinal plant [2].

The members of this genus contain secondary metabolites like isatin, indicant, indirubin, tryptanthrin, p-coumaric acid, quercetin, chlorogenic acid, p-OH benzoic acid, caffeic acid [2,3] and have antioxidant, antimicrobial, anti-inflammatory and antinociceptive properties $[3,4]$. These plants are used for rheumatism, asthma, ulcer, constipation, fever, tumor, eczema, bite and hemorrhoid [5-7]. In addition, it has been reported that I. glauca subsp. glauca, I. glauca subsp. iconia and I. tinctoria are traditionally used for the wound healing in Turkey $[8,9]$.

Wounding is one of the oldest and basic health problems in human history. Since the human body heals wounds by itself as an innate ability, wound healing may be overlooked. However, it is a highly complex and sensitive physiological process consisting of intertwi- ned stages (inflammation, proliferation, remodeling) [10]. Many factors can disrupt this process and decrease the quality of life by delaying or preventing healing. Diabetes mellitus is one of these factors and is a systemic disease characterized by hyperglycemia [11]. In diabetic patients, almost all stages of the wound healing process are damaged. The diabetic wound healing process is disrupted due to the complications such as reduced collagen and growth factors production, infection, changing cellular activities, oxidative stress, vascular diseases and neuropathy $[11,12]$.

The collagen is the dominant protein of the extracellular matrix (ECM) in the dermal layer of the skin, and is a vital element of the wound healing process [13]. Additionally, nitric oxide (NO) is a significant message molecule synthesized by various cell types in the skin during the healing process [14]. It has been reported that collagen and nitric oxide levels decrease in diabetic wounds $[15,16]$.

Alternative treatment methods have been investigated in order to promote and accelerate diabetic wound healing process. This study was carried out to evaluate 
the phenolic compounds of I. glauca subsp. sivasica (locally known as Sivas çiviti) extract and examine the effects of the extract on collagen and nitric oxide levels and wound closure rates throughout diabetic healing process on day 3 and 7 .

\section{MATERIAL AND METHODS}

\section{Plant Materials}

I. glauca subsp. sivasica (Davis) Yıldırımlı samples were collected from Kemah/Erzincan province (between Kemah-Erzincan roadside, 1300-1400 m) in Turkey and were identified by Dr. Mustafa Karaköse. The voucher specimens have been deposited at the Espiye Vocational School Herbarium, Giresun University (Voucher number: ESPH 20)

\section{Preparation of the Isatis Extract}

The collected and identified plant samples (aerial parts) were dried under shade. Powdered samples (5 g) were extracted with methanol $(100 \mathrm{~mL})$ using Soxhlet apparatus. After the filtration with Whatman Millipore filter paper, methanol was evaporated by using a rotary evaporator (The yields of the extract: $15.69 \% \mathrm{w} / \mathrm{w}$ from dried starting material).

\section{Reverse phase-high performance liquid chromatography method with diode array detector (RP-HPLC-DAD) analysis}

The analysis was obtained according to a previously described method [17]. The gradient program was set by using the binary solvent system (A: distilled water with $2 \%$ acetic acid, B: distilled water with $70 \%$ acetonitrile, initial condition $5 \% \mathrm{~B}$, final condition $60 \% \mathrm{~B}$, run time 26 min). The column was operated at temperature of $30{ }^{\circ} \mathrm{C}$ The flow of mobile phase and injection volume were adjusted as $1.2 \mathrm{~mL} / \mathrm{min}$ and $10 \mu \mathrm{L}$, respectively. The eluted 10 phenolic acid standards and 2 flavonoids were analyzed at $280 \mathrm{~nm}$ by using a reversed phase column (Table 1). The validation parameters such as limits of detection (LOD) and limits of quantification (LOQ) were calculated to present much more reliably quantified results about analyses. Briefly, the phenolic compounds of the Isatis extract were evaluated by RP-HPLC-DAD using the calibration and validation values of the studied standard phenolic compounds (Table 1).

\section{Induction of the Diabetes Model}

This study was conducted with the approval from Gazi University Local Ethics Committee for Animal Experi- ments (G.Ü.ET-15.052). 24 Wistar rats were accommodated in standard cages with rat food and water (at room temperature, normal light-dark cycle). The diabetes model was induced in all rats via single dose intraperitoneal freshly prepared streptozotocin (STZ) (Sigma, USA) solution injection $(60 \mathrm{mg} / \mathrm{kg}$ in sodium citrate buffer, $\mathrm{pH}$ 4.5). Three days after STZ injection, glucose levels were determined by a commercial glucometer, and those with above $250 \mathrm{mg} / \mathrm{dL}$ were considered as diabetic.

\section{Induction of Wound Model}

The animals were anesthetized with IM ketamine and xylazine. The dorsum of the rat was shaved and cleansed. Full thickness excisional skin wounds (six per animal) were created by using a biopsy punch (8-mm, Acu-Punch, Acuderm, USA) in all rats. The animals were randomly divided into four groups under two main groups (control and Isatis).

1. Control day 3: Wounded, no treatment was applied, sacrificed at post wounding day $3(n=6)$

2. Control day 7: Wounded, no treatment was applied, sacrificed at post wounding day $7(n=6)$

3. Isatis day 3: Wounded, the Isatis extract was applied, sacrificed at post wounding day $3(n=6)$

4. Isatis day 7: Wounded, the Isatis extract was applied, sacrificed at post wounding day $7(n=6)$

The Isatis extract was dissolved in $500 \mathrm{~mL}$ of physiological saline and the dose was adjusted such that $50 \mathrm{mg} / \mathrm{kg}$ of plant extract was applied to each wound (approx. $1 \mathrm{~mL}$ solution) based on the weight of the rats. In the treatment groups, the Isatis extract was applied topically to wounds via a sterile pipette as a single daily dose until sacrifice. The animals were sacrificed under anesthesia at post wounding day 3 or day 7 , and wound tissue samples were collected. The collected samples were stored at $-80^{\circ} \mathrm{C}$. Simultaneously, the punch samples representing day 0 were also collected from the animals of the same groups.

\section{Measurement of Collagen Levels}

The collagen assay kit (Biocolor, UK) was used to measurement of the total collagen amount (type I-V) in the wound tissues. Collagen levels were determined according to the manufacturer's protocol and Tsuda et al. [18]. Briefly, the collected samples were homogenized in pepsinacetic acid solution overnight, and mixed with Sircol dye reagent. Finally, the absorbances were recorded spectrophotometrically at $540 \mathrm{~nm}$. 
Table 1. The calibration and validation values of the studied standard phenolic compounds

\begin{tabular}{|c|c|c|c|c|c|c|c|}
\hline No & $R T$ & Standarts & $R^{2}$ & $R S D \%(R T)$ & RSD\%(Area) & $L O D\left(m g L^{-1}\right)$ & $\operatorname{LOQ}\left(m g L^{-1}\right)$ \\
\hline 1 & $3.72 \pm 0.006$ & Gallic acid & 0.999 & 0.168 & $4 \cdot 315$ & 0.070 & 0.213 \\
\hline 2 & $6.74 \pm 0.019$ & Protocatechuic acid & 0.998 & 0.291 & 5.973 & 0.495 & 1.499 \\
\hline 3 & $10.13 \pm 0.029$ & p-OH Benzoic acid & 0.999 & 0.290 & 4.817 & 0.224 & 0.680 \\
\hline 4 & $11.46 \pm 0.027$ & Chlorogenic acid & 0.997 & 0.239 & 6.177 & 0.512 & 1.550 \\
\hline 5 & $13.49 \pm 0.023$ & Vanillic acid & 0.994 & 0.168 & 6.794 & 0.171 & 0.518 \\
\hline 6 & $13.84 \pm 0.032$ & Caffeic acid & 0.999 & 0.235 & 6.861 & 0.058 & 0.175 \\
\hline 7 & $14.79 \pm 0.012$ & Syringic acid & 0.999 & 0.082 & 5.116 & 0.096 & 0.290 \\
\hline 8 & $16.41 \pm 0.010$ & $p$-Coumaric acid & 0.999 & 0.061 & 2.935 & 0.005 & 0.014 \\
\hline 9 & $16.63 \pm 0.012$ & Rutin & 0.999 & 0.075 & 2.855 & 0.311 & 0.942 \\
\hline 10 & $18.41 \pm 0.013$ & Rosmarinic acid & 0.999 & 0.069 & 3.388 & 0.162 & 0.492 \\
\hline 11 & $18.84 \pm 0.014$ & Benzoic acid & 0.999 & 0.076 & 2.721 & 0.550 & 1.665 \\
\hline 12 & $21.71 \pm 0.019$ & Quercetin & 0.999 & 0.087 & 2.268 & 0.335 & 1.014 \\
\hline
\end{tabular}

\section{Determination of $\mathrm{NO}_{\mathrm{x}}$ Levels}

The levels of $\mathrm{NO}_{x}$ in the wound tissue were evaluated according to a previously described method [19]. $\mathrm{NO}_{\mathrm{x}}$ levels were calculated by Griess reagent assay. Briefly, the collected samples were homogenized in phosphate buffer ( $\mathrm{pH}$ 7), and mixed with Griess reagents (N-1naphthylethylenediamine dihydrochloride and sulphanilamide). After, the absorbances were recorded spectrophotometrically at $540 \mathrm{~nm}$. Sodium nitrite and sodium nitrate solutions were used as standards.

\section{Determination of Wound Size and Wound Closure Rate (WCR)}

The wounds were photographed during the healing process. The wound sizes and the wound closure rates are assessed and measured using the ImageJ software $(\mathrm{NIH}$, USA). The WCR was calculated as follows:

WCR $(\%)=[($ wound size day $0-$ wound size on day 3 or 7)/wound size day 0$] \times 100$.

\section{Statistical Analysis}

The obtained results were presented as the mean \pm standard deviation (SD), and were compared using one-way ANOVA post-hoc Tukey test. Results with $\mathrm{P}<0.001$ were interpreted as statistically significant (SPSS version 16, IBM, USA).

\section{RESULTS}

\section{Phenolic Compounds}

The RP-HPLC-DAD analysis revealed that Isatis extract contained protocatechuic acid, rutin, vanillic acid, p-hydroxybenzoic acid, rosmarinic acid, p-coumaric acid, caffeic acid, and benzoic acid (Fig. 1). Benzoic acid (6.95 mg phenolic/g extract) and vanillic acid (2.88 mg phenolic/g extract) were major phenolics in Isatis extract (Table 2). Gallic acid, chlorogenic acid, syringic acid and quercetin were not detected (Table 2).
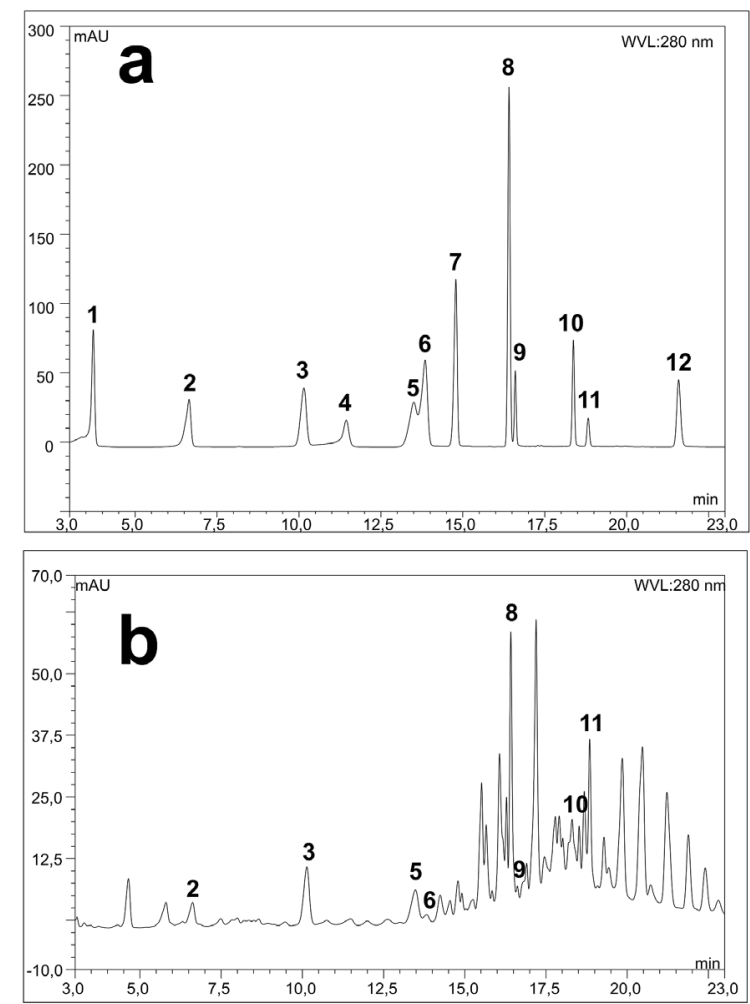

Figure 1. Chromatogram of I. glauca subsp. sivasica extract (a) standard phenolic compounds (b) Isatis (1) gallic acid (2) protocatechuic acid (3) p-OH-benzoic acid (4) chlorogenic acid (5) vanillic acid (6) caffeic acid (7) syringic acid (8) p-coumaric acid (9) rutin (10) rosmarinic acid (11) benzoic acid (12) quercetin 
Table 2. Phenolic compounds of I. glauca subsp. sivasica extract

\begin{tabular}{|c|c|c|}
\hline & \multirow{2}{*}{ Phenolic Compounds } & \multirow{2}{*}{$\frac{\text { Isatis glauca subsp. sivasica }}{\text { mg phenolic/g extract }}$} \\
\hline & & \\
\hline 1 & Gallic acid & n.d. \\
\hline 2 & Protocatechuic acid & 0.705 \\
\hline 3 & p-OH Benzoic acid & 1.783 \\
\hline 4 & Chlorogenic acid & n.d. \\
\hline 5 & Vanillic acid & 2.879 \\
\hline 6 & Caffeic acid & 0.103 \\
\hline 7 & Syringic acid & n.d. \\
\hline 8 & p-Coumaric acid & 1.158 \\
\hline 9 & Rutin & 0.194 \\
\hline 10 & Rosmarinic acid & 0.652 \\
\hline 11 & Benzoic acid & 6.954 \\
\hline 12 & Quercetin & n.d. \\
\hline & Total & 14.432 \\
\hline
\end{tabular}

n.d. = not dedected

\subsection{Collagen and $\mathrm{NO}_{x}$ Levels}

Topically administrated Isatis extract altered collagen and $\mathrm{NO}_{\mathrm{x}}$ levels in diabetic wound tissue on both day 3 and day 7 compared to the control group as shown in Table 3. On day 3 and day 7, statistically increased collagen amount was determined in the Isatis group compared to the control group $(\mathrm{P}<0.001)$ (Fig. 2). Similarly, $\mathrm{NO}_{x}$ levels in the Isatis group were also elevated significantly on day 3 and day 7 compared to the control group $(\mathrm{P}<$ 0.001) (Fig. 3).

\section{Wound Sizes and WCRs}

Fig. 4 shows the statistically significant decrease of wound size after Isatis extract administration on day 3 and day 7 compared to control group $(\mathrm{P}<0.001)$. Isatis group

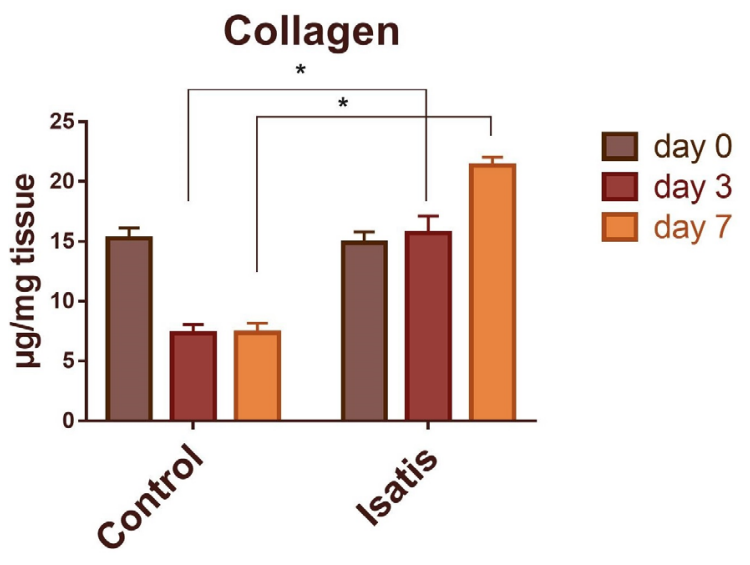

Figure 2. Comparison of Isatis and control groups in terms of collagen

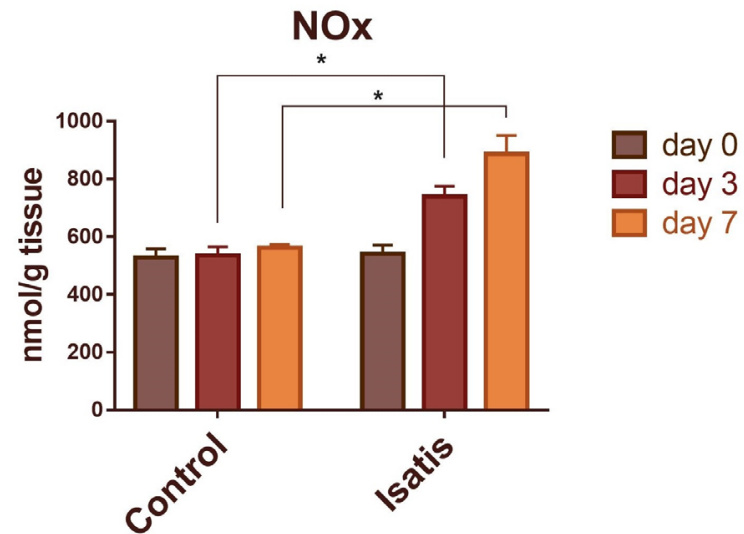

Figure 3. Comparison of Isatis and control groups in terms of NOx levels

displayed a higher WCR on day 3 and day 7 compared to control group (Table 4).

\section{DISCUSSION}

Since the wound healing is impaired in patients with diabetes, it is very important in terms of the life quality. New healing methods are increasingly gaining attention and are being researched in order to promote the diabetic wound healing process. Plant extracts have been used for this purpose since ancient times. This work aimed to investigate the effect of I. glauca subsp. sivasica extract on wound healing process of the STZ-induced diabetic Wistar rats. The I. glauca subsp. sivasica was chosen for this work because I. glauca and its various subspecies are traditionally used in the treatment of wounds as reported in ethnobotanical works $[8,9]$.

The family of phenolic compounds are generally categorized into two class termed as phenolic acids and flavonoids. Besides ten phenolic acids, two flavonoids were analyzed for calibration and identification in this work. Our results showed that different ranges of concentration of pro-

Table 3. The collagen and NOx levels in diabetic wound tissue

\begin{tabular}{lll}
\hline & $\begin{array}{l}\text { Collagen } \\
(\mu \mathrm{g} / \mathrm{mg} \text { tissue })\end{array}$ & $\begin{array}{c}\text { NOx } \\
\text { (nmol/g tissue) }\end{array}$ \\
\hline Control group & & \\
\hline dayo & $15,24 \pm 0,87$ & $528,26 \pm 30,41$ \\
day3 & $7,32 \pm 0,73$ & $535,43 \pm 30,38$ \\
day7 & $7,36 \pm 0,81$ & $562,10 \pm 11,27$ \\
\hline Isatis group & $14,88 \pm 0,93$ & $541,26 \pm 30,22$ \\
\hline day0 & $15,72 \pm 1,40 *$ & $739,20 \pm 36,00 *$ \\
day3 & $21,32 \pm 0,74 *$ & $887,04 \pm 64,04 *$ \\
day7 &
\end{tabular}

${ }^{*} \mathrm{P}<0.001$ compared to control group on same day 


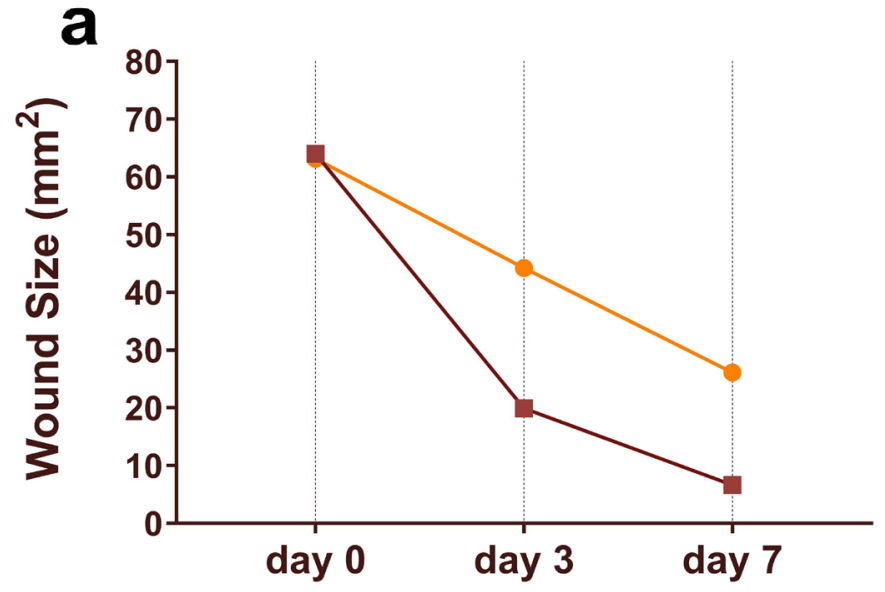

- Control

- Isatis

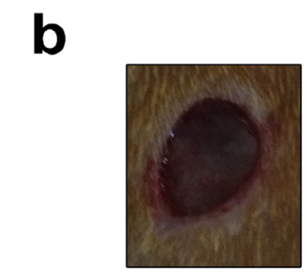

An example of the full thickness excisional skin wound model

\section{post-wounding}

Figure 4. (a) Comparison of Isatis and control groups in terms of wound sizes depending on time (b) an example of the full thickness excisional skin wound model

\begin{tabular}{ll}
\hline & Wound size $\left(\mathrm{mm}^{2}\right)$ and WCR (\%) \\
\hline Control group & \\
\hline dayo & $63,15 \pm 3,48$ \\
day 3 & $44,22 \pm 2,41(29,97 \%)$ \\
day7 & $26,11 \pm 1,72(58,65 \%)$ \\
\hline Isatis group & \\
\hline dayo & $64,03 \pm 3,17$ \\
day 3 & $19,94 \pm 2,56 *(68,86 \%)$ \\
day7 & $6,64 \pm 0,98^{*}(89,63 \%)$ \\
\hline
\end{tabular}

${ }^{\star} \mathrm{P}<0.001$ compared to control group on same day

Table 4. Wound sizes and WCRs during diabetic wound healing process

tocatechuic acid, rutin, vanillic acid, p-hydroxybenzoic acid, rosmarinic acid, p-coumaric acid, caffeic acid, and benzoic acid were contained in the Isatis extract. Phenolic compounds are commonly used in the treatment of various disorders thanks to its antioxidant and antimicrobial activity [17] The Isatis extract can be considered as a source of bioactive compounds. The evaluated outputs are nearly similar to the phenolic compounds of the other members of the Isatis genus. Karakoca et al. [3] reported that I. floribunda contains phenolic components such as p-hydroxybenzoic acid, catechin, chlorogenic acid, caffeic acid, ferulic acid, quercetin, cinnamic acid and p-coumaric acid. In another study, Miceli et al. [20] showed that chlorogenic acid, sinapic acid, caffeic acid, ferulic acid, rutin, p-coumaric acid, apigenin-glucoside, isovitexin and vicenin-2 detected in I. tinctoria.

Collagen and $\mathrm{NO}$ are two important molecules that play a role in the complex wound healing process. Collagen is a major ECM component made up of amino acids (3 chains in triple helix form), and it accounts for about 75\% of dry weight of the human skin. The synthesis, accumulation, deposition and degradation of collagen are important for proper wound healing process [21]. An important task of collagen is to increase the wound tensile strength by providing a structural support [13]. NO, an endogenous gasotransmitter, is synthesized from L-arginine by nitric oxide synthases (NOS), and has roles in the regulation of antimicrobial action, vascular homeostasis and inflammation during the wound healing process [16]. It has been demonstrated that both collagen and NO content decreased in the wounds of diabetes-induced animals and chronic wounds of diabetic patients $[15,16]$. These decreases may be one of the underlying causes of the damaged wound healing in diabetic patients. In our study, a statistically significant elevation in collagen and $\mathrm{NO}_{x}$ levels on days 3 and 7 were founded in the Isatis group compared with the control group.

However, there is no study showing the effects of I. glauca subsp. sivasica or another Isatis species on collagen and NO contents in the literature. These effects of Isatis may be due to its chemical composition. Kumar et al. [22] showed that the administration of vanillic acid increases NO levels in hypertensive rats. Additionally, it has reported that rutin enhances $\mathrm{NO}$ and collagen production in endothelial and fibroblast cells, respectively [23,24]. Isatis extract may also have increased the collagen and $\mathrm{NO}$ level due to the vanillic acid and rutin content (Table 2).

According to Kizll et al. [25], palmitic, oleic, erucic, stearic, linoleic and linolenic acids were detected in the fatty acid composition of I. glauca. Lambertucci et al. [26] reported that palmitic acid induces $\mathrm{NO}$ production and of inducible nitric oxide synthases (iNOS) protein content in 
muscle cells. Additionally, de Lima et al. [27] demonstrated that fatty acids (palmitic, stearic, oleic, linoleic acids) increase NO production in macrophages at low concentrations. Taken together, these results suggest that I. glauca subsp. sivasica extract can increase NO content in diabetic wound tissue through the composition of fatty acids and phenolic compounds. Furthermore, NO enhances the production and deposition of collagen during wound healing in nondiabetic or diabetic experimental models [28-31]. Hence, it can be stated that Isatis glauca subsp. sivasica extract contributes to diabetic healing process via increased collagen and nitric oxide levels.

Wound closure occurs due to the movement and proliferation of epithelial cells at the edge of the wound area (called as epithelialization). Diabetes mellitus causes nonclosing (non-healing) wounds or impaired wound healing [11]. In our study, a statistically significant decrease in the wound sizes were measured in the Isatis group compared to the control group on day 3 and day 7 ( $\mathrm{p}<0,001)$. In addition, WCRs detected in the Isatis group reached about 69\% and $90 \%$, in contrast to only $30 \%$ and $59 \%$ in the control group on day 3 and 7, respectively. The presented results suggested that this Isatis species accelerates the wound healing process supporting its traditional use.

\section{CONCLUSION}

This work shows that I. glauca subsp. sivasica extract can contribute to promote diabetic wound healing process by increasing collagen and NO levels and WCR on days 3 and 7. In this context, the I. glauca subsp. sivasica extract can be a potential therapeutic agent for the management of diabetic wounds.

\section{CONFLICT OF INTEREST}

Authors approve that to the best of their knowledge, there is not any conflict of interest or common interest with an institution/organization or a person that may affect the review process of the paper.

\section{AUTHOR CONTRIBUTION}

Kaan Kaltalioglu and Sule Coskun Cevher designed the study. KK performed all experiments. KK and SCC analysed the data. KK and SCC wrote the paper.

\section{References}

1. Güner A, Aslan S, Ekim T, Vural M, Babaç MT. Türkiye Bitkileri Listesi (Damarlı Bitkiler), first ed. Flora Araştırmaları Derneği ve Nezahat Gökyiğit Botanik Bahçesi Yayını, İstanbul, 2012.

2. Yıldız N, Karakaş Ö. Qualitative and Quantitative Determination of Tryptanthrin, Indirubin, Indican and Isatin Indole Alkaloids
During Vegetative and Flowering Stages in the Roots and Leaves of Isatis constricta P. H. Davis. Tarla Bitkileri Merkez Araştırma Enstitüsü Dergisi 28 (2019) 59-66.

3. Karakoca K, Özüsağlam MA, Çakmak YS, Erkul SK. Antioxidative, antimicrobial and cytotoxic properties of isatis floribunda boiss. ex bornm. Extracts. EXCLI Journal 12 (2013) 150-167.

4. Küpeli E, Orhan İ, Yeşilada E. Evaluation of Some Plants Used in Turkish Folk Medicine for Their Anti-inflammatory and Antinociceptive Activities. Pharmaceutical Biology 45 (2007) 547-555.

5. Hamburger M. Isatis tinctoria - From the Rediscovery of an Ancient Medicinal Plant Towards a Novel Anti-Inflamatory Phytopharmaceutical. Phytochemistry Reviews 1 (2002) 333-344.

6. Tuzlacı E, Doğan A. Turkish folk medicinal plants, IX: Ovacık (Tunceli). Marmara Pharmaceutical Journal 14 (2010) 136-143.

7. Rezaeipoor R, Ziaei Sanei L, Kamalinejad M. Effects of Isatis cappadocica on humoral immune responses. Fitoterapia 71 (2000) 14-18.

8. Ozturk M, Uysal I, Gucel S, Altundag E, Dogan Y, Baslar S. Medicinal Uses of Natural Dye-Yielding Plants in Turkey. Research Journal of Textile and Apparel 17 (2013) 69-80.

9. Baytop T. Therapy with Plants in Turkey (Past \& Present), second ed. Nobel Tip, İstanbul, 1999.

10. Guo S, DiPietro LA. Factors Affecting Wound Healing. Journal of Dental Research 89 (2010) 219-229.

11. Li H, Fu X, Zhang L, Huang Q, Wu Z, Sun T. Research of PDGF-BB gel on the wound healing of diabetic rats and its pharmacodynamics. Journal of Surgical Research 145 (2008) 41-48.

12. Kaltalioglu K, Balabanli B, Coskun-Cevher S. Phenolic, Antioxidant, Antimicrobial, and In-vivo Wound Healing Properties of Potentilla erecta L. Root Extract in Diabetic Rats. Iranian Journal of Pharmaceutical Research 19 (2020) 264-274.

13. Brett D. A review of collagen and collagen-based wound dressings. Wounds 20 (2008) 347-356.

14. Schäfer M, Werner S. Oxidative stress in normal and impaired wound repair. Pharmacological Research 58 (2008) 165-171.

15. Blakytny R, Jude E. The molecular biology of chronic wounds and delayed healing in diabetes. Diabetic Medicine 23 (2006) 594-608.

16. Malone-Povolny MJ, Maloney SE, Schoenfisch MH. Nitric Oxide Therapy for Diabetic Wound Healing. Advanced Healthcare Materials 8 (2019) e1801210.

17. Bektas E, Kaltalioglu K, Sahin H, Turkmen Z, Kandemir A. Analysis of phenolic compounds, antioxidant and antimicrobial properties of some endemic medicinal plants. International Journal of Secondary Metabolite 5 (2018) 75-86.

18. Tsuda K, Nakatani T, Sugama J, Okuwa M, Sanada H. Influence of the timing of switching a protein-free to a protein-containing diet on the wound healing process in a rat all-layer skin defect. International Wound Journal 7 (2010) 135-146.

19. Miranda KM, Espey MG, Wink DA. A rapid, simple spectrophotometric method for simultaneous detection of nitrate and nitrite. Nitric Oxide 5 (2001) 62-71.

20. Miceli N, Filocamo A, Ragusa S, Cacciola F, Dugo P, Mondello L, Celano M, Maggisano V, Taviano MF. Chemical characterization and biological activities of phenolic-rich fraction from cauline leaves of Isatis tinctoria L. (Brassicaceae) growing in Sicily, Italy. Chemistry \& Biodiversity 14 (2017) e1700073.

21. dos Santos Gramma LS, Marques FM, Vittorazzi C, de Andrade, TAM, Frade MAC, de Andrade TU, Endringer DC, Scherer R, Fronza M. Struthanthus vulgaris ointment prevents an over expression of inflammatory response and accelerates the cutaneous wound healing. Journal of Ethnopharmacology 190 (2016) 319-327. 
22. Kumar S, Prahalathan P, Raja B. Antihypertensive and antioxidant potential of vanillic acid, a phenolic compound in l-NAMEinduced hypertensive rats: A dose-dependence study. Redox Report 16 (2011) 208-215.

23. Ugusman A, Zakaria Z, Chua KH, Nordin NAMM, Abdullah Mahdy Z. Role of rutin on nitric oxide synthesis in human umbilical vein endothelial cells. Scientific World Journal (2014) 2014: 1-9.

24. Choi SJ, Lee SN, Kim K, Joo da H, Shin S, Lee J, Lee HK, Kim J, Kwon SB, Kim MJ, Ahn KJ, An IS, An S, Cha HJ. Biological effects of rutin on skin aging. International Journal of Molecular Medicine 38 (2016) 357-363

25. Kızıl S, Turk M, Çakmak Ö, Özgüven M, Khawar KM. Microelement Contents and Fatty Acid Compositions of some Isatis Species Seeds. Notulae Botanicae Horti Agrobotanici Cluj-Napoca 37 (2009) 175-178.

26. Lambertucci RH, Leandro CG, Vinolo MA, Nachbar RT, Dos Reis Silveira L, Hirabara SM, Curi R, Pithon-Curi TC. The effects of palmitic acid on nitric oxide production by rat skeletal muscle: mechanism via superoxide and iNOS activation. Cellular Physiology and Biochemistry 30 (2012) 1169-1180.

27. de Lima TM, de Sa Lima L, Scavone C, Curi R. Fatty acid control of nitric oxide production by macrophages. FEBS Letters 580 (2006) 3287-3295.

28. Witte MB, Thornton FJ, Efron DT, Barbul A. Enhancement of fibroblast collagen synthesis by nitric oxide. Nitric Oxide 4 (2000) 572-582.

29. Witte MB, Kiyama T, Barbul A. Nitric oxide enhances experimental wound healing in diabetes. British Journal of Surgery 89 (2002) 1594-1601.

30. Achuth HN, Moochhala SM, Mahendran R, Tan WT. Nitrosoglutathione triggers collagen deposition in cutaneous wound repair. Wound Repair and Regeneration 13 (2005) 383-389.

31. Luo J, Chen AF. Nitric oxide: a newly discovered function on wound healing. Acta Pharmacologica Sinica 26 (2005) 259-264. 